\title{
Lift Truck Load Stress in Concrete Floors
}

\author{
Vinicius Fernando Arcaro, Luiz Carlos de Almeida \\ University of Campinas, Campinas, Brazil \\ Email: vinicius.arcaro@gmail.com
}

How to cite this paper: Arcaro, V.F. and de Almeida, L.C. (2017) Lift Truck Load Stress in Concrete Floors. Open Journal of Civil Engineering, 7, 245-251. https://doi.org/10.4236/ojce.2017.72015

Received: April 29, 2017

Accepted: June 10, 2017

Published: June 13, 2017

Copyright ( 92017 by authors and Scientific Research Publishing Inc. This work is licensed under the Creative Commons Attribution International License (CC BY 4.0).

http://creativecommons.org/licenses/by/4.0/

\begin{abstract}
This text presents an analytical expression to calculate the maximum tension, at the bottom side of a concrete slab on ground, due to lift truck wheel loads. The result of the analytical expression is in close agreement with the result of a design chart by the Portland Cement Association and with the result of a finite element analysis. The analytical expression is able to show the relationships among the design variables and it can be used for the thickness design of concrete floors for factories and warehouses. The expression applies only to unreinforced concrete slabs on ground.
\end{abstract}

\section{Keywords}

Concrete, Design, Slabs on Ground

\section{Introduction}

In general, the analytical expressions found in the literature about slab on ground present several inconveniences. The expressions were derived before the advent of electronic calculators and the use of slide rules to evaluate mathematical constants resulted in numbers with low accuracy. Typographical mistakes may have been introduced in their subsequent transcription. In references [1] and [2], which are classical texts, the expressions are in US Customary Units, mixing feet and inches. Finally, some expressions are presented with a fixed modulus of elasticity while other expressions have a safety factor included, as in reference [2]. For the case of a lift truck load, an analytical expression is presented and checked with a design chart and with a finite element analysis.

\section{Analytical Expression}

Considering $E$ as the modulus of elasticity, $v$ as the Poisson's ratio, $h$ as the thickness of the plate and $k$ as the modulus of soil reaction, according to reference [3], for a concentrated force distributed over an area $A$, in the interior point of a plate on elastic foundation, the stresses on the bottom side at a point $(x, y)$ 
can be written as:

$$
\begin{aligned}
& \sigma_{x}=\frac{3 P}{2 \pi h^{2}}\left\{(1+v)\left[\ln (2 \lambda)-\mu-I_{1}\right]+(1-v)\left(\frac{1}{2}-I_{2}\right)\right\} \\
& \sigma_{y}=\frac{3 P}{2 \pi h^{2}}\left\{(1+v)\left[\ln (2 \lambda)-\mu-I_{1}\right]-(1-v)\left(\frac{1}{2}-I_{2}\right)\right\}
\end{aligned}
$$

where,

$$
\begin{gathered}
\lambda^{4}=\frac{E h^{3}}{12\left(1-v^{2}\right) k} \\
\mu=\lim _{n \rightarrow \infty}\left(\sum_{k=1}^{n} \frac{1}{k}-\ln n\right) \approx 0.577216
\end{gathered}
$$

Figure 1 shows the geometrical parameters involved in the evaluation of the stresses on the bottom side of the plate at a point $(x, y)$ due to a concentrated force distributed over an area $A$. The distance from point $(x, y)$ to a point $(u, v)$ inside area $A$ is given by $w$. The angle of the line between the points $(x, y)$ and $(u, v)$ with the $\mathrm{X}$-axis is given by $\omega$. The difficulty in calculating the stresses lies in the calculation of the integrals $I_{1}$ and $I_{2}$.

$$
\begin{gathered}
I_{1}(x, y)=\frac{1}{A} \int_{A} \ln (w) \mathrm{d} A \\
I_{2}(x, y)=\frac{1}{A} \int_{A} \cos ^{2}(\omega) \mathrm{d} A
\end{gathered}
$$

\section{Integrals for the Circle}

Figure 2 shows the geometrical parameters involving in the evaluation of the stresses on the bottom side of the plate in a point $(x, y)$ due to a concentrated force distributed over a circle of radius $R$. The integrals for the circle were solved by traditional manual computations with the help of reference [4]. Computer algebra systems were not able to solve it.

$$
x<R \Rightarrow I_{1}(x)=\ln R+\frac{1}{2}\left(\frac{x^{2}}{R^{2}}-1\right)
$$

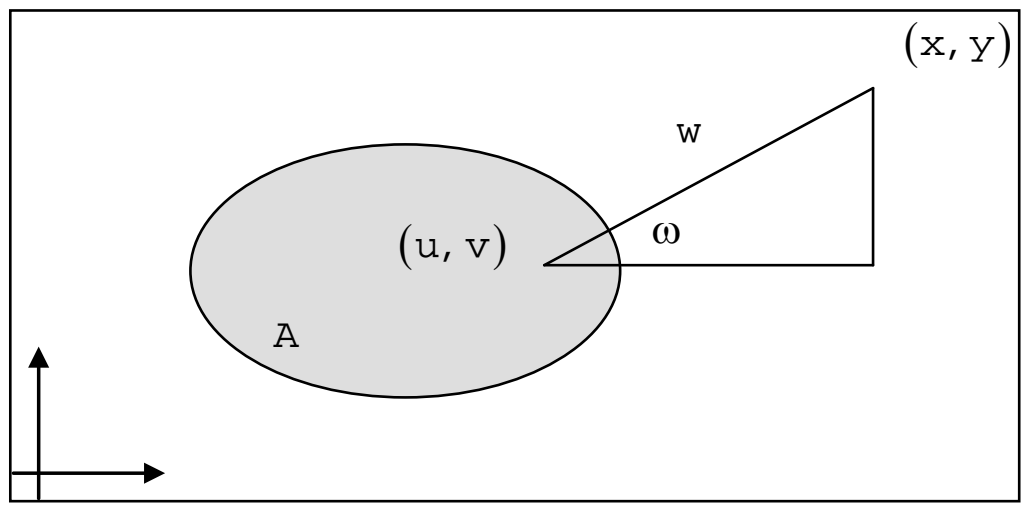

Figure 1. Concentrated force distributed over an area $A$. 


$$
\begin{gathered}
x>R \Rightarrow I_{1}(x)=\ln x \\
x<R \Rightarrow I_{2}(x)=\frac{1}{4}\left(2+\frac{x^{2}}{R^{2}}\right) \\
x>R \Rightarrow I_{2}(x)=\frac{1}{4}\left(4-\frac{R^{2}}{x^{2}}\right)
\end{gathered}
$$

\section{Lift Truck}

Figure 3 shows the lift truck load as two equal concentrated forces, each distributed over a circle of radius $R$, separated by a distance $\mathrm{d}$. The stress on the bottom side of the plate, at the center of each circle, can be written as:

$$
\sigma_{y}=\sigma_{y}(0)+\sigma_{y}(\mathrm{~d})
$$

Due to three dimensional effects, the expressions for the stresses are not accurate in the neighborhood of the center of a very small circle. However, reference [5] suggests that these expressions can be used to evaluate the stress at the center of the circle by using a modified radius according to the following expression:

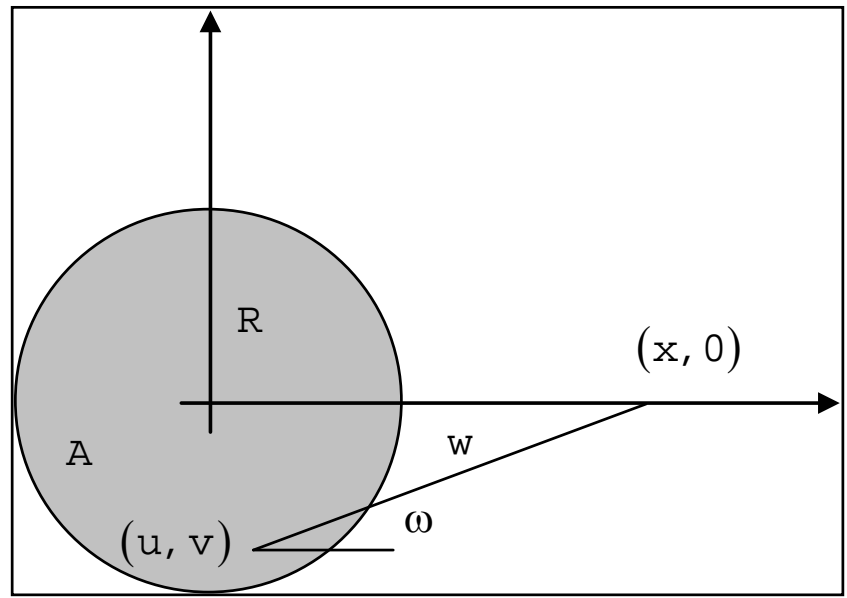

Figure 2. Concentrated force distributed over a circle.

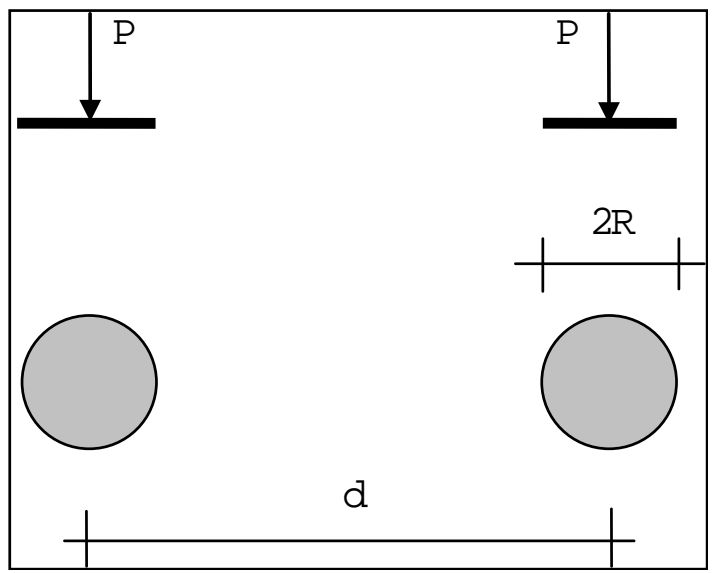

Figure 3. Lift truck load. 


$$
\bar{R}= \begin{cases}\sqrt{1.6 R^{2}+h^{2}}-0.675 h & R<1.724 h \\ R & R \geq 1.724 h\end{cases}
$$

This suggestion leads to the following expression for the stress, on the bottom side of the plate, at the center of each circle:

$$
\sigma_{y}=\frac{3 P}{2 \pi h^{2}}\left\{(1+v)\left[\ln \left(\frac{4 \lambda^{2}}{\bar{R} d}\right)-2 \mu+\frac{1}{2}\right]+\frac{1}{4}(1-v)\left(2-\frac{R^{2}}{d^{2}}\right)\right\}
$$

The contact area may be estimated for pneumatic tires by dividing wheel load by inflation pressure. According to reference [6] and [7], the equivalent inflation pressure for solid tires is between $180 \mathrm{lbf} / \mathrm{in}^{2}$ e $250 \mathrm{lbf} / \mathrm{in}^{2}$.

\section{Design Example}

This design example was taken from reference [8]. For comparison, the original US Customary Units used in the example were used with the analytical expression and with the ANSYS finite element analysis software from reference [9]. Consider a slab on ground with thickness equal to 7.9 in $(0.20 \mathrm{~m})$. The modulus of soil reaction is equal to $100 \mathrm{lbf} / \mathrm{in}^{3}\left(2.71 \mathrm{E}+07 \mathrm{~N} / \mathrm{m}^{3}\right)$. The axle load is equal to $25,000 \mathrm{lbf}(111,206 \mathrm{~N})$. The tire pressure is equal to $110 \mathrm{lbf} / \mathrm{in}^{2}\left(7.58 \mathrm{E}+05 \mathrm{~N} / \mathrm{m}^{2}\right)$. The wheel spacing is equal to 37 in $(0.94 \mathrm{~m})$. The modulus of elasticity of concrete is equal to $4,864,000 \mathrm{lbf} / \mathrm{in}^{2}\left(3.35 \mathrm{E}+10 \mathrm{~N} / \mathrm{m}^{2}\right)$. The tire contact area can be calculated by dividing the wheel load by the tire pressure. The maximum tension, calculated with the design chart, is equal to $320 \mathrm{lbf} / \mathrm{in}^{2}(2.21 \mathrm{MPa})$.

\subsection{Analytical Expression}

Applying expression (13) developed for the stress at the center of each circle with the data taken from reference [8], gives the maximum tension at the bottom side of the concrete slab on ground equal to $343.72 \mathrm{lbf} / \mathrm{in}^{2}$ (2.37 MPa).

\subsection{Finite Element Analysis with ANSYS}

The maximum tension at the bottom side of a concrete slab on ground is equal to $348.32 \mathrm{lbf} / \mathrm{in}^{2}(2.40 \mathrm{MPa})$. The maximum tension is about $1 \%$ above the value obtained by the analytical expression. The wheel loads were applied at about three times the radius of relative stiffness from the plate edges. Figure 4 shows the stress in the $y$ direction at the bottom side of the slab. The ANSYS input listing for calculating the stress in the $y$ direction at the bottom side of the slab is:

! Enters the model creation preprocessor

/PREP7

! Creates a circular area

CYL4, $-18.5,0.0,0.0,, 6.014281,, 0.0$

! Creates a circular area

CYL4, 18.5, 0.0, 0.0, , 6.014281, , 0.0

! Groups geometry items into a component 


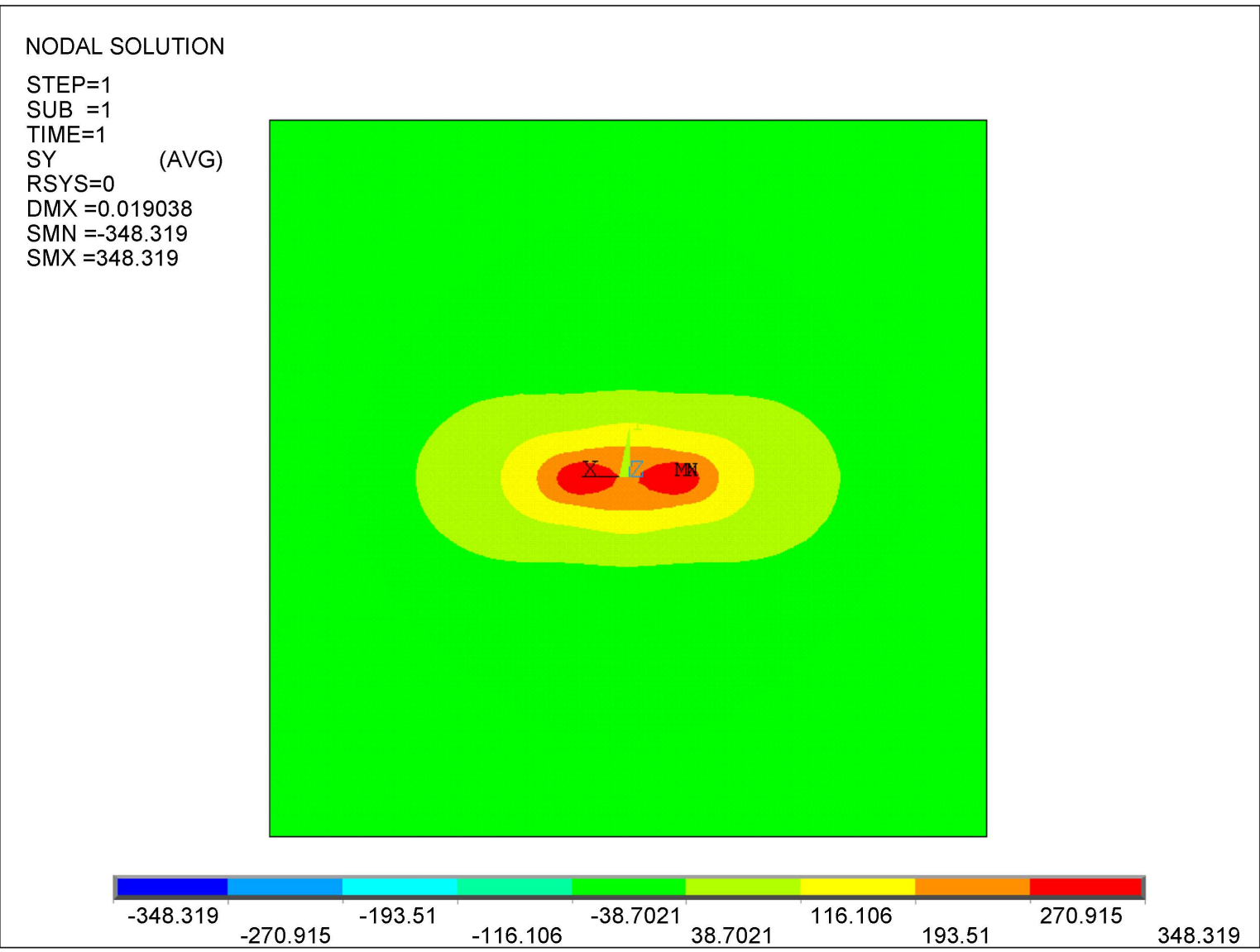

Figure 4. Stress in the $y$ direction at the bottom side of the slab.

CM, Cname, AREA

! Selects a subset of components

CMSEL, ALL, Cname

! Creates a rectangular area by corner points

BLC4, -132.0, -132.0, 264.0, 264.0, 0.0

! Subtracts areas from areas

ASBA, 3, Cname, , DELETE, KEEP

! Generates new areas by gluing areas

AGLUE, ALL

! Define element type

ET, 1, SHELL63

! Define element real constants

$\mathrm{R}, 1,7.9$, , , , 100.0

! Define material property

MP, EX, 1, 4.864E+06

MP, PRXY, 1, 0.20

! Specify the divisions on unmeshed lines

LESIZE, ALL, 2.0

! Generate nodes and elements

AMESH, ALL 
Table 1. Maximum tension at the bottom side of the concrete slab on ground.

\begin{tabular}{ccc}
\hline PCA & Expression (13) & FEA \\
\hline $320.00 \mathrm{lbf} / \mathrm{in}^{2}$ & $343.72 \mathrm{lbf} / \mathrm{in}^{2}$ & $348.32 \mathrm{lbf} / \mathrm{in}^{2}$ \\
$2.21 \mathrm{MPa}$ & $2.37 \mathrm{MPa}$ & $2.40 \mathrm{MPa}$ \\
\hline
\end{tabular}

! Define constraints

$\mathrm{N} 1=\operatorname{NODE}(-132.0,-132.0,0.0)$

$\mathrm{D}, \mathrm{N} 1, \mathrm{UX}, 0.0$

D, N1, UY, 0.0

! Specifies surface loads on the selected areas

SFA, Cname, 2, PRES, 110.0

FINISH

\section{Results}

Table 1 shows a comparison of the maximum tension at the bottom side of the concrete slab on ground. The results were obtained using the PCA design chart, the analytical expression and a finite element analysis. The differences in the results are negligible. The relative error when comparing the analytical expression with the finite element analysis is about $1 \%$.

\section{Conclusion}

The analytical expression to calculate the maximum tension, at the bottom side of a concrete slab on ground due to lift truck wheel loads, was evaluated using expressions from theory of Elasticity presented in reference [3]. The analytical expression can replace the design chart that is usually employed in the design procedure because its result is in good agreement either with the design chart itself or with a finite element analysis. The analytical expression can also be used for checking finite element codes. It should be noticed that highly accurate numerical solutions in the form of finite element analysis have been presented in the literature. However, simple analytical expressions are preferred because they are able to show the relationships among the design variables.

\section{References}

[1] Ringo, B. (1992) Designing Floor Slabs on Grade. Hanley Wood.

[2] Packard, R.G. (1996) Slab Thickness Design for Industrial Concrete Floors on Grade. Portland Cement Association, Skokie.

[3] Westergaard, H.M. (1943) Stress Concentrations in Plates Loaded over Small Areas. Transactions ASCE, 108, 831-856.

[4] Gradshteyn, I.S. and Ryzhik, I.M. (2000) Table of Integrals, Series, and Products. 6th Edition, Academic Press, San Diego.

[5] Westergaard, H.M. (1926) Stresses in Concrete Pavements Computed by Theoretical Analysis. Public Roads, 7, 25-35.

[6] Off-the-Road Tires Engineering Data (1983) Goodyear Tire \& Rubber Company, Engineering Reports. 
[7] Over-the-Road Tires Engineering Data (1985) Goodyear Tire \& Rubber Company, Engineering Reports.

[8] Spears, R.E. (1992) Concrete Floors on Ground. 2nd Edition, Portland Cement Association, Skokie.

[9] ANSYS, Inc. (2016) Canonsburg, PA 15317, USA.

\section{Scientific Research Publishing}

Submit or recommend next manuscript to SCIRP and we will provide best service for you:

Accepting pre-submission inquiries through Email, Facebook, LinkedIn, Twitter, etc. A wide selection of journals (inclusive of 9 subjects, more than 200 journals)

Providing 24-hour high-quality service

User-friendly online submission system

Fair and swift peer-review system

Efficient typesetting and proofreading procedure

Display of the result of downloads and visits, as well as the number of cited articles Maximum dissemination of your research work

Submit your manuscript at: http://papersubmission.scirp.org/

Or contact ojce@scirp.org 